$\Phi=$

\title{
DiGeorge syndrome and immune thrombocytopenia purpura
}

\author{
Amna Mohsin MRCP ${ }^{1}$, Mahasin Shaheen MD MRCP ${ }^{2}$ \\ ${ }^{1}$ Lister hospital East and North Hertfordshire NHS trust, U.K \\ ${ }^{2}$ Al Qassimi Hospital, Al Khezamia, Sharjah, UAE \\ *Corresponding author E-mail: am_rawalian@hotmail.com
}

\begin{abstract}
Digeorge Syndrome (22q11.2 deletion syndrome) comprises of various congenital anomalies such as cardiac defects, specific facial appearances, defective $\mathrm{T}$ cell production, hypocalcemia etc. This syndrome is also associated with various autoimmune diseases. Here we present a case report which shows association of Immune thrombocytopenia purpura with Digeorge Syndrome. A 15 years old boy born with congenital cardiac defects, diagnosed as 22q11.2 deletion syndrome, underwent corrective cardiac surgeries after birth. He developed thrombocytopenia at this age, requiring admission and platelet transfusions. His further work up confirmed Immune thrombocytopenic purpura and its presentation being related to the genetic disorder itself.
\end{abstract}

Keywords: Cleft Palate; Congenital Cardiac Anomalies; 22q11.2 Deletion; Digeorge Syndrome; Immune Thrombocytopenic Purpura; Purpuric Rash.

\section{Introduction}

DiGeorge Syndrome (DGS), also designated as 22q11.2 deletion syndrome, encompasses of phenotypically similar disorders including velocardiofacial syndromes and conotruncal anomaly face syndrome. All these disorders primarily consist of microdeletion of chromosome 22 at a location known as 22q11.2 also termed as DGS critical region. It occurs in about 1 in 4000 to 1 in 7000 births (Goodship 1998, Óskarsdóttir 2004). Almost 90\% of the occurrence is due to sporadic microdeletion of chromosome 22 (McDonald-McGinn 1999). This syndrome consists of various features often includes congenital heart defects, cleft palate, frequent infections, developmental delay, learning disabilities and hypocalcemia. Kidney problems, hearing deficits and autoimmune disorders may also be associated with DGS. Patients with DiGeorge syndrome develop the autoimmune disease at a rate higher than the general population. Autoimmunity can be attributed to defective T cell production in DiGeorge Syndrome. Tison (2011) reviewed the occurrence of autoimmunity in a large cohort of pediatric patients and found out that cytopenia and hypothyroidism were the most common autoimmune conditions. Therefore autoimmune diseases in Digeorge syndrome are immune thrombocytopenia purpura (Lévy 1997) immune cytopenia (DePiero 1997), juvenile rheumatoid arthritis like polyarthritis (Sullivan 1997) and grave's disease (Ham Pong 1985, Kawamura 2000). Here we present a case report of a boy who was diagnosed with DiGeorge syndrome on birth as was born with congenital cardiac anomalies, dysmorphic facial features and later developed ITP.

\section{CASE}

15 years old boy of Arab origin of healthy parents (non-consanguineous marriage) was diagnosed to have DiGeorge syndrome at birth, had interrupted aortic arch (type B) with anomalous origin of a right subclavian artery from descending aorta and ventricular septal defect. He had a repair of aortic arch and VSD at an age of 3 weeks at a tertiary hospital. He was diagnosed as DiGeorge syndrome in this hospital at an age of 4 years, he had a transaortic resection of discrete subaortic stenosis with a good outcome.

He had been following in the pediatric department and now in the medical department of this hospital.

\subsection{History of presenting illness}

He presented to the Emergency Department of the hospital on $21^{\text {st }}$ April 2018 with a complaint of non-traumatic minimal nasal bleeding followed by a small amount of upper lip bleeding of one-day duration Purpuric rash in the postauricular area was noted by the mother. Another purpuric lesion was noted in the right upper limb region in ER which was not itchy or tender. There was no recent history of nasal, oral or auricular bleeding. The patient denied any history of fever or flu-like symptoms. Review of rest of systems was negative.

\subsection{Past medical history}

History of frequent infections in childhood.

Past history of admission in December 2016 with thrombocytopenia, was given platelet transfusions and discharged. Pregnancy was uneventful without any complications. 
He was delivered by spontaneous vaginal delivery and birth weight was $3.4 \mathrm{~kg}$. At an age of 3 days, he was admitted in ICU in a state of shock. He improved on prostaglandin administration in addition to ventilation and inotropic support. He was then transferred to the pediatric cardiology department at an age of 9 days and eventually referred to NHS trust hospital for further intervention.

\subsection{Family history}

There is no significant family history of such similar condition, mental retardation or epilepsy. However, one of his paternal cousins had a sudden cardiac arrest at an age of 20 years (cause unknown and was healthy, previously).

\subsection{Vaccination history}

Up to date.

\subsection{Development}

Poor school performance $65 \%$ NCE. Studying in a normal public school but requires special assistance.

He has left eye amblyopia and wears corrective eyeglasses.

Milestones were normal according to mother.

\subsection{Physical examination}

General: alert oriented, no acute distress, dysmorphic facial features, hypertelorism.

Small thrombosed clot on the upper right inner lip. Purpuric non-blanching, non-tender rash in right postauricular and right upper limb.

Height: $155 \mathrm{~cm}$, Weight: $47.4 \mathrm{~kg}$, Body Mass Index: 20

Cardiovascular: Normal rate, regular rhythm, normal peripheral perfusion.

Grade 2 /6 systolic murmur at upper left sternal edge.

Respiratory: lungs clear to auscultation; breath sounds equal bilateral.

Gastrointestinal: soft, no organomegaly

Neurology: normal

Psychiatric: cooperative

Vitals:

Afebrile

Pulse 75 bpm

Respiratory Rate $17 / \mathrm{min}$

Blood pressure: $110 / 60 \mathrm{mmHg}$

\subsection{Review management}

Blood results revealed severe thrombocytopenia 7 x 10(3)/mcl, WBCS were 3.75 x 10(3)/mcl, Hb 14 g/dl, PTT 35.80, INR 1.13. Urea and electrolytes, liver function tests, PTH, thyroid hormones, calcium, magnesium, phosphorus, CRP, procalcitonin, ANA screen, CMV Ig m, and EBV Ig M were all normal. Peripheral blood film showed macrothrombocytopenia, normal RBCs and WBCS.

Chest $\mathrm{x}$-ray: normal

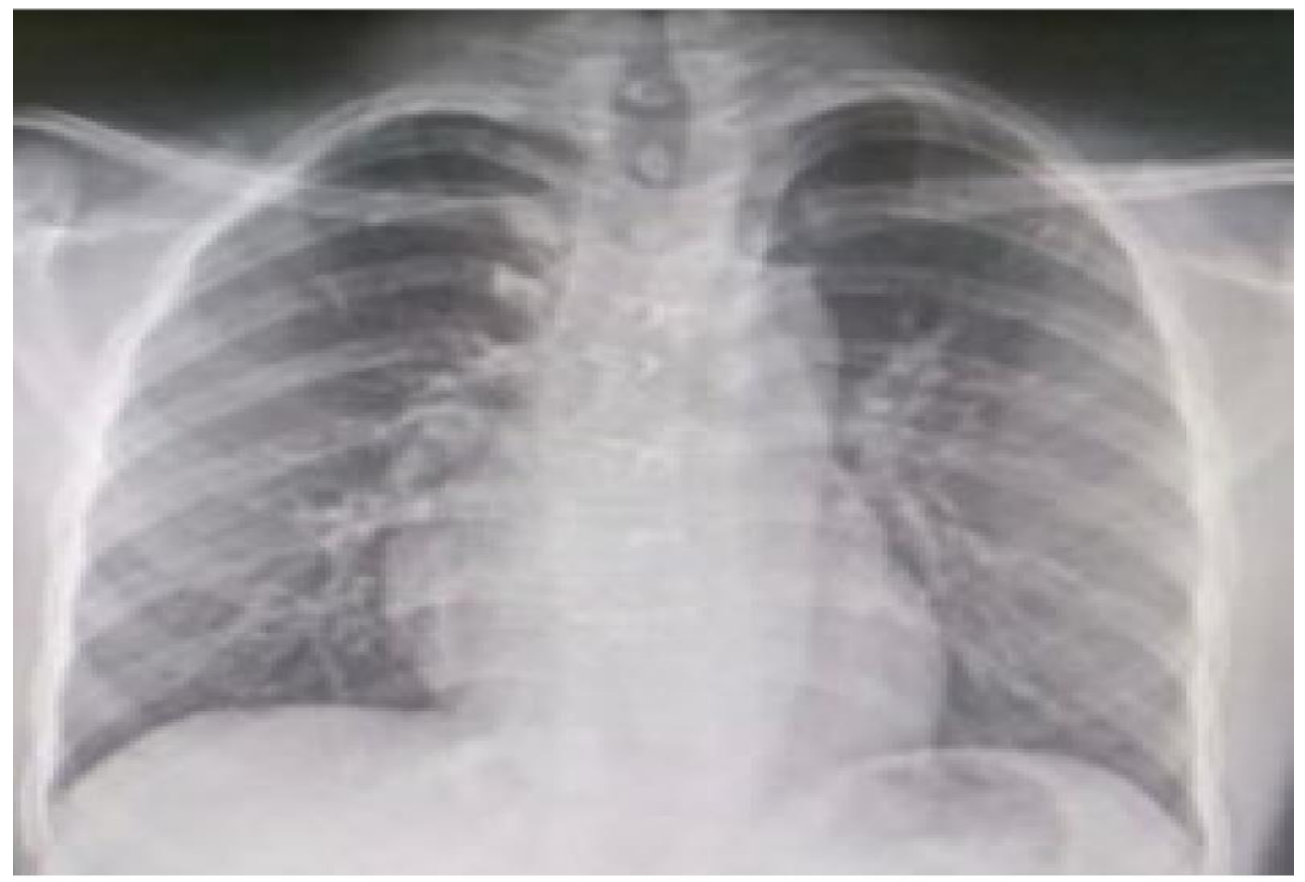

Abdominal and pelvic ultrasound was normal.

The patient was admitted under the impression of possible immune thrombocytopenia purpura. He was started on immunoglobulin and prednisolone. During his stay in the hospital, there was no more bleeding or bruising. He responded to therapy and his platelets im- 
proved. On discharged on 25/4 his platelets were 132 x 10(3)/mcl, WBC 6.76 x 10(3)/mcl, Hb 13.90 g/dl, INR 0.97. He was discharged on $40 \mathrm{mg}$ prednisolone. He was referred to hematology department of a tertiary hospital where it was confirmed to be ITP and has been on steroids since then.

Recent cardiac evaluation and Echocardiography report on $26^{\text {th }}$ March 2019:

\section{ECHOCARDIOGRAPHY REPORT}

\begin{tabular}{|c|c|c|c|c|}
\hline M-Mode & & Normal & & Normal \\
\hline Aorta & $28 \mathrm{mms}$ & \begin{tabular}{l|l} 
& LVID [D] \\
\end{tabular} & $43 \mathrm{~mm}$ & \\
\hline Ao. V & & LVID [S] & $29 \mathrm{~mm}$ & \\
\hline $\mathbf{L A}$ & $24 \mathrm{mms}$ & IVS [D] & $12 \mathrm{~mm}$ & \\
\hline RIVD [D] & $12 \mathrm{mms}$ & IVS [S] & $14 \mathrm{~mm}$ & \\
\hline RIVD [S] & & LVPW [D] & $11 \mathrm{~mm}$ & \\
\hline IAS & Intact & LVPW [S] & $13 \mathrm{~mm}$ & \\
\hline $\begin{array}{l}\text { Pericardiu } \\
\text { m }\end{array}$ & No PE & EF\% & $62 \%$ & \\
\hline
\end{tabular}

Normal situs solitus, levocardia, atrio-ventricular concordance, ventricle-arterial concordance, normal great arteries relationship.

Pulmonary veins drain to left atrium and systemic veins drain to right atrium normally. Normal right atrium, normal left atrium, intact IAS.

trivial mitral valve regurgitation, mild tricuspid valve regurgitation .RVSP $25 \mathrm{mmHg}$.

Mild Concentric LVH with normal systolic function.

Normal RV dimensions and functions. Intact intra-ventricular septum.

Sub aortic membrane $12 \mathrm{~mm}$ in size. Outflow tract is $21 \mathrm{~mm}$ (reduced by $50 \%$ ) and aortic valve opening 6-7mm. Aortic valve (bicuspid) area 1.2 sqcms. AV PGmax 69/32 mmHg, Valsalva maneuver $70 / 34 \mathrm{mmHg}$. Annulus $20 \mathrm{mms}$

Normal pulmonary valve.

Normal aorta with normal left aortic arch (mild gradient across the dec aorta $27 \mathrm{~mm} \mathrm{Hg}$ ). .

Normal main pulmonary artery and pulmonary branches .

\subsection{Blood results from 2014-2019}

Past blood results revealed thrombocytopenia from 2016 onwards. Also revealed frequent low total WBCS with low absolute neutrophil count and seldom low lymphocyte count.

\section{Discussion}

This is a case of DiGeorge syndrome presenting with immune thrombocytopenic purpura which responded to steroids. All past labs from 2016 onwards showed thrombocytopenia and fewer times showed low absolute neutrophil, lymphocyte count and leukopenia.

The incidence of Immune thrombocytopenic purpura in people with 22q11DS is approximately 200 times more common than in the general population (Akar 2007, Liang 2007). The higher incidence of autoimmune disorders in DiGeorge syndrome is partly due to the depressed expression of AIRE(autoimmune regulator)in the thymus, eventually leading to decreased negative selection of autoreactive $\mathrm{T}$ cells (Bawle 2018). The severity and prevalence of immune deficits present in 22q11. 2DS are highly variable, although complete thymic aplasia is rare. The immunodeficiency found in children sometimes persists into adulthood. In this patient, low WBC can be due to frequent viral infections attributed to immunodeficiency itself and secondly low absolute lymphocyte count can be associated with thymic hypoplasia. Thus, immune thrombocytopenia and other hematological abnormalities seen in 22q11DS are due to the genetic disorder itself.

\section{Conclusion}

A multidisciplinary approach is required for individuals with 22q11.2DS. The primary physician also must monitor growth and development. A system-by-system approach results in the best outcome.

- For hypoparathyroidism-associated hypocalcemia: Calcium supplementation and vitamin D supplementation may also be needed.

- Corrective surgeries for congenital cardiac anomalies, cleft palate and, for congenital anterior glottic webs, tracheotomy or surgical reconstruction.

- Regular monitoring of full blood counts to look out for cytopenias. Therapies for immunodeficiencies include thymus transplantation in case of rare complete DiGeorge syndrome (Markert 2007). To follow up regularly for any autoimmune complications in partial DiGeorge syndrome.

\section{References}

[1] Akar, N. A. a. A., A. D. (2007). "Chromosome 22q11.2 Deletion Presenting with Immune-Mediated Cytopenias, Macrothrombocytopenia and Platelet Dysfunction." Medical Principles and Practice 16(4): 318-320. https://doi.org/10.1159/000102157.

[2] Bawle, E. V. (2018). "Digeorge Syndrome(Disease mechanism of autoimmune disease)." Medscape.

[3] DePiero, A. D., Lourie, E. M., Berman, B. W. Robin, N. H., Zinn, A. B. and Hostoffer, R. W. (1997). "Recurrent immune cytopenias in two patients with DiGeorge/velocardiofacial syndrome." The Journal of Pediatrics 131(3): 484-486. https://doi.org/10.1016/S0022-3476(97)80085-6.

[4] Goodship, J., Cross, I., Liling, J. and Wren. C. (1998). "A population study of chromosome 22q11 deletions in infancy." Archives of Disease in Childhood 79(4): 348-351. https://doi.org/10.1136/adc.79.4.348.

[5] Ham Pong, A. J., Cavallo, A., Holman, G. H. and Goldman, A. S. (1985). "DiGeorge syndrome: Long-term survival complicated by Graves disease." The Journal of Pediatrics 106(4): 619-620. https://doi.org/10.1016/S0022-3476(85)80087-1. 
[6] Kawamura, T., Nimura, I. Hanafusa, M., Fujikawa, R., Okubo, M., Egusa, G. and Yamakido, M. (2000). "NOTE DiGeorge Syndrome with Graves' Disease: A Case Report." Endocrine Journal 47(1): 91-95. https://doi.org/10.1507/endocrj.47.91.

[7] Lévy, A., Michel, G., Lemerrer, M. and Philip, N. (1997). "Idiopathic thrombocytopenic purpura in two mothers of children with DiGeorge sequence: A new component manifestation of deletion 22q11?" American Journal of Medical Genetics 69(4): 356-359. https://doi.org/10.1002/(SICI)1096-8628(19970414)69:4<356::AID-AJMG4>3.0.CO;2-J.

[8] Liang, H. P. H., Morel-Kopp, M. C., Curtin, J., Wilson, M., Hewson, J., Chen, W. and Ward, C. M. (2007). "Heterozygous loss of platelet glycoprotein (GP) Ib-V-IX variably affects platelet function in velocardiofacial syndrome (VCFS) patients." Thromb Haemost 98(12): 1298-1308. https://doi.org/10.1160/TH07-05-0350.

[9] Markert, M. L., Devlin, B. H. Alexieff, M. J., Li, J., McCarthy, E. A., Gupton, S. E., Chinn, I. K., Hale, L. P., Kepler, T. B. He, M., Sarzotti, M., Skinner, M. A. and Hoehner, J. C. (2007). "Review of 54 patients with complete DiGeorge anomaly enrolled in protocols for thymus transplantation: outcome of 44 consecutive transplants." Blood 109(10): 4539-4547. https://doi.org/10.1182/blood-2006-10-048652.

[10] McDonald-McGinn, D. M., Emanuel, B.S. and Zackai, E.H. . (1999, Updated 2013 Feb 28). "22q11.2 Deletion Syndrome." Adam MP, Ardinger HH, Pagon RA, et al., editors. GeneReviews ${ }^{\circledR}$ [Internet]from https://www.ncbi.nlm.nih.gov/books/NBK1523/.

[11] Óskarsdóttir, S., Vujic, M. and Fasth, A (2004). "Incidence and prevalence of the 22q11 deletion syndrome: a population-based study in Western Sweden." Archives of Disease in Childhood 89(2): 148-151. https://doi.org/10.1136/adc.2003.026880.

[12] Sullivan, K. E., McDonald-McGinn, D. M., Driscoll, D. A. Zmijewski, C. M., Ellabban, A. S. Reed, L., Emanuel, B. S., Zackai, E. H., Athreya, B. H. and Keenan, G. (1997). "Juvenile rheumatoid arthritis-like polyarthritis in chromosome 22q11.2 deletion syndrome (digeorge anomalad/velocardiofacial syndrome/conotruncal anomaly face syndrome)." Arthritis \& Rheumatism 40(3): 430-436. https://doi.org/10.1002/art.1780400307.

[13] Tison, B. E., Nicholas, S. K., Abramson, S. L., Hanson, I. C., Paul, M. E., Seeborg, F. O., Shearer, W. T., Perez, M. D., Noroski, L. M. and Chinen, J. (2011). "Autoimmunity in a cohort of 130 pediatric patients with partial DiGeorge syndrome." Journal of Allergy and Clinical Immunology 128(5): 1115-1117.e1113. https://doi.org/10.1016/j.jaci.2011.06.043. 